OPEN ACCESS

Edited by:

Mihajlo Jakovljevic, Hosei University, Japan

Reviewed by:

Amâncio António De Sousa Carvalho, University of Trás-os-Montes and Alto

Douro, Portugal

Roberta Markovic,

University of Niš, Serbia

*Correspondence:

Zoltán Vokó

voko.zoltan@semmelweis-univ.hu

Specialty section:

This article was submitted to

Health Economics,

a section of the journal

Frontiers in Public Health

Received: 01 June 2021 Accepted: 02 August 2021 Published: 27 August 2021

Citation:

Aboulghate M, Elaghoury A Elebrashy I, Elkafrawy $N$,

Elshishiney G, Abul-Magd E,

Bassiouny E, Toaima D, Elezbawy B,

Fasseeh A, Abaza S and Vokó Z

(2021) The Burden of Obesity in

Egypt. Front. Public Health 9:718978.

doi: 10.3389/fpubh.2021.718978

\section{The Burden of Obesity in Egypt}

\author{
Mohamed Aboulghate ${ }^{1}$, Aliaa Elaghoury ${ }^{2}$, Ibrahim Elebrashy ${ }^{3}$, Nabil Elkafrawy ${ }^{4}$, \\ Galal Elshishiney ${ }^{5}$, Ehab Abul-Magd ${ }^{6}$, Engy Bassiouny ${ }^{7}$, Dalia Toaima ${ }^{7}$, Baher Elezbawy ${ }^{8}$, \\ Ahmad Fasseeh ${ }^{8,9}$, Sherif Abaza ${ }^{8}$ and Zoltán Vokó ${ }^{10,11 *}$ \\ ${ }^{1}$ Department of Anesthesiology, Cairo University, Cairo, Budapest, Egypt, ${ }^{2}$ Department of Endocrinology, Alexandria \\ University, Alexandria, Egypt, ${ }^{3}$ Department of Internal Medicine, Cairo University, Cairo, Egypt, ${ }^{4}$ Department of Internal \\ Medicine, Endocrinology Unit, Menofia University, Menofia, Egypt, ${ }^{5}$ Ministry of Health and Population, Cairo, Egypt, \\ ${ }^{6}$ Egyptian Health Care Management Society, Cairo, Egypt, ${ }^{7}$ Novo Nordisk, Cairo, Egypt, ${ }^{8}$ Syreon Middle East, Alexandria, \\ Egypt, ${ }^{9}$ Department of Social Sciences, Eötvös Loránd University, Budapest, Hungary, ${ }^{10}$ Center for Health Technology \\ Assessment, Semmelweis University, Budapest, Hungary, ${ }^{11}$ Syreon Research Institute, Budapest, Hungary
}

Objective: Estimating the burden of obesity to society is an essential step in setting priorities and raising awareness. We aimed to assess the clinical, humanistic and economic burden of obesity for adults in Egypt.

Methods: We used the population attributable fraction concept to estimate the burden. A non-systematic review was conducted to estimate the prevalence of obesity and its comorbidities in addition to the obesity attributable fraction. Patient numbers, direct healthcare costs, disability adjusted life years (DALYs) and attributable mortality were estimated.

Results: Obesity is a major contributor to the development of diabetes mellitus, hypertension, obstructive sleep apnea and fatty liver, in addition to several serious diseases. The estimated annual deaths due to obesity was about 115 thousand $(19.08 \%$ of the total estimated deaths in 2020). DALYs attributable to obesity may have reached 4 million in 2020. The economic burden imposed by obesity is around 62 Billion Egyptian pounds annually. This value is the cost of treating diseases attributable to obesity in adults.

Conclusions: Diseases attributable to obesity create a huge economic, humanistic, and clinical burden in Egypt. Reducing obesity could help dramatically decrease the catastrophic health effect of these diseases which in turn decreases mortality and DALYs lost.

Keywords: cost analysis, epidemiology, health policy, obesity, mortality

\section{INTRODUCTION}

Annually, about 4.7 million premature deaths occur due to obesity. It was ranked fifth among the leading preventable causes of death (1), making up 8.4\% of deaths worldwide in 2017 (2).

According to the World Health Organization (WHO), Egypt ranks $18^{\text {th }}$ with the highest prevalence of obesity worldwide (3). Deaths attributable to non-communicable diseases represent about $71 \%$ of the total mortality burden (4).

Very few studies have been published about the burden of diseases in Egypt in general, and the burden of obesity is even more complex as the impact of obesity is a result of its comorbidities (5) rather than a direct effect, which makes it more difficult to estimate the burden of obesity. There is not any published study which has specifically attempted to evaluate the economic burden of obesity in Egypt. 
Estimating the societal burden of obesity is an essential step in setting priorities for research and public health interventions. It also helps to raise public awareness about the negative impacts of obesity and provides health policy decision-makers with information about the magnitude of health problems (6). Some studies do not consider obesity as a disease, as it may not have substantial direct costs or related pain (7), although it is included in the International Classification of Diseases and Related Health Problems (8). The clear fact is that obesity is a risk factor for several costly and disabling diseases (7).

Our objective was to estimate the burden of obesity in Egypt. This study evaluates the clinical, humanistic, and economic burden of obesity in adults in Egypt.

\section{MATERIALS AND METHODS}

We utilized both primary (expert interviews) and secondary (publications and payers' services list) data sources to estimate the annual cost per patient per year for each comorbidity. For the considered diseases, we calculated the number of patients attributable to obesity using the population attributable fraction concept. We also estimated the annual economic burden, mortalities, and disability adjusted life years (DALYs). To estimate the prevalence of obesity among the adult population in Egypt, we used the results of 100 million health survey conducted in 2019 (unpublished data from personal communication). Obesity was defined as having a body mass index (BMI) $\geq 30$ throughout this study based on WHO definition (9).

\section{Diseases Attributable to Obesity}

To identify the diseases attributable to obesity, a non-systematic review was conducted through PubMed, Google and Google Scholar search engines. The search was conducted on $16^{\text {th }}$ of April 2020 with no time restriction. The search key can be found in Supplementary Table 1. We included studies that list the comorbidities associated with obesity. Finally, a primary list was based on five studies. This was followed by expert interviews to validate the included diseases. Finally, 13 diseases were included in the analysis: type 2 diabetes mellitus, hypertension, ischemic heart disease, hyperlipidemia, stroke, sleep apnea, osteoarthritis, gall bladder disease, colon and colorectal cancer, breast cancer, endometrial cancer, depression and fatty liver.

\section{Estimating Population Attributable Fraction}

The population attributable fraction of obesity for a disease (i.e., the percent of patients having this disease due to obesity) depends on the relative risk of disease, and the prevalence of obesity. The following formula was used for the calculation:

$$
P A F=1-\left(\frac{1}{1-P+R R^{*} P}\right),
$$

where PAF stands for population attributable fraction, $\mathrm{P}$ for the prevalence of obesity, and RR for relative risk.

The proportion of population diseased attributable to obesity was calculated by multiplying the obesity attributable fraction (OAF) with the prevalence of the disease in the adult population for each sex. (e.g., $61.8 \%$ of diabetic male patients are diabetic due to obesity $(O A F), 13.86 \%$ of males have diabetes (prevalence), the calculation would be $61.8 \% * 13.86 \%=8.56 \%$ of the total population have diabetes due to obesity).

To calculate the number of patients who have the disease due to obesity, the proportion of population diseased attributable to obesity (PAF) was multiplied by the number of adult populations by sex. (e.g., $8.56 \% * 30$ million $=2.75$ million patients).

\section{Prevalence}

Egypt National STEPwise Survey 2017 was utilized to obtain the prevalence of diabetes, hypertension and hyperlipidemia (10), which provided an estimate for the prevalence of total cholesterol $\geq 5.0 \mathrm{mmol} / \mathrm{L}$, that was used as a proxy for hyperlipidemia. As the survey was based on measurements and not on interview, the total prevalence of these comorbidities could be estimated not only the diagnosed cases. For diabetes mellitus, the value was further adjusted to the proportion of type 2 only (11).

The global burden of disease (GBD) study prevalence estimates were used for most of the remaining diseases (11). These values were estimated for Egypt in 2017 and published by the Institute for Health Metrics and Evaluation (IHME) (12). Sleep apnea prevalence was estimated through a study by Franklin et al. in 2014 (13). Prevalence of fatty liver in Egypt was not found in the literature. We used a rough estimate of worldwide prevalence reported by Binobaid et al. in 2018 being 20-30\% (14). We assumed Egypt would be in the midline and used the $25 \%$ value as an estimate for fatty liver prevalence in Egypt. Prevalence estimates and their sources are presented in Table 1.

\section{Relative Risks}

Relative risks of diseases for obesity vs. no obesity were found in the literature. Most values were based on a meta-analysis conducted in 2009 by Guh et al. (16) Relative risk for obstructive sleep apnea was estimated to be seven-fold. (17) For fatty liver, ischemic heart disease and hyperlipidemia, values were abstracted from Li et al., (18) Jee et al. (19), and Fu et al. (20), respectively. Table 2 shows the relative risks of obesity associated diseases.

\section{Humanistic Burden}

To estimate the number of deaths attributable to obesity, the obesity attributable fraction of each disease was multiplied by the number of deaths due to the disease in the total population. The estimated number of deaths due to each disease is published in the IHME database (12). We calculated the population attributable fraction of mortality only for major causes of death.

The global burden of disease study had estimates of DALY values in Egypt for several diseases (11). These values were multiplied by obesity attributable fraction to estimate the value of DALYs attributable to obesity.

Hyperlipidemia DALYs attributable to high cholesterol in the Eastern Mediterranean region was shown in a figure in the global health risks study (21). For obstructive sleep apnea (OSA), DALYs were based on a study that estimated DALYs lost due to sleep disorders among which obstructive sleep apnea is a main 
TABLE 1 | Prevalence of obesity and its comorbidities in Egypt.

\begin{tabular}{|c|c|c|c|c|}
\hline Disease & Prevalence total & Prevalence males & Prevalence females & References \\
\hline Obesity (BMI $\geq 30)$ & $39.82 \%$ & $29.51 \%$ & $49.49 \%$ & 100 million health survey $2019^{a}$ \\
\hline Diabetes mellitus & $15.16 \%$ & $13.86 \%$ & $16.46 \%$ & $\begin{array}{l}\text { Egypt National STEPwise Survey } \\
\text { (10), GBD } 2015 \text { (15) }\end{array}$ \\
\hline Hypertension & $29.50 \%$ & $29.80 \%$ & $29.20 \%$ & Egypt National STEPwise Survey (10) \\
\hline Ischemic heart disease (CHD/CAD) & $2.71 \%$ & $3.23 \%$ & $2.16 \%$ & GBD 2015 (15) \\
\hline Hyperlipidemia (total cholesterol $\geq 5.0 \mathrm{mmol} / \mathrm{L}$ ) & $19.20 \%$ & $14.90 \%$ & $23.40 \%$ & Egypt National STEPwise Survey (10) \\
\hline stroke & $1.74 \%$ & $1.64 \%$ & $1.86 \%$ & GBD 2015 (15) \\
\hline Obstructive sleep apnea & NA & $22.0 \%$ & $17.0 \%$ & Franklin et al. (13) \\
\hline Depression & $4.16 \%$ & $3.23 \%$ & $5.15 \%$ & GBD 2015 (15) \\
\hline Colon and colorectal cancer & $0.030 \%$ & $0.03 \%$ & $0.03 \%$ & GBD 2015 (15) \\
\hline Breast cancer & $0.142 \%$ & $0.00 \%$ & $0.29 \%$ & GBD 2015 (15) \\
\hline Endometrial cancer & $0.016 \%$ & $0.00 \%$ & $0.03 \%$ & GBD 2015 (15) \\
\hline Gall bladder disease & $0.717 \%$ & $0.46 \%$ & $0.99 \%$ & GBD 2018 (15) \\
\hline Osteoarthritis & $5.022 \%$ & $4.85 \%$ & $5.20 \%$ & GBD 2018 (15) \\
\hline Fatty liver & $20-30 \%$ & $25 \%$ & $25 \%$ & Binobaid et al. (14) \\
\hline
\end{tabular}

NA, not available.

a http://www.emro.who.int/ar/egy/egypt-events/hepatitis-c-elimination.html.

TABLE 2 | Relative risks of diseases in people with obesity.

\begin{tabular}{lccl}
\hline Disease & $\begin{array}{c}\text { Relative risk } \\
\text { in males }\end{array}$ & $\begin{array}{c}\text { Relative risk } \\
\text { in females }\end{array}$ & References \\
\hline Diabetes mellitus & 6.47 & 12.41 & Guh et al. (16) \\
Hypertension & 1.84 & 2.42 & Guh et al. (16) \\
Ischemic heart disease & 4.37 & 4.37 & Jee et al. (19) \\
Hyperlipidemia & 1.76 & 1.76 & Fu et al. (20) \\
Stroke & 1.51 & 1.49 & Guh et al. (16) \\
Sleep apnea & 7.00 & 7.00 & Carol (17) \\
Depression & 1.31 & 1.67 & Guh et al. (16) \\
Colon and colorectal cancer & 1.95 & 1.66 & Guh et al. (16) \\
Breast cancer & - & 1.13 & Guh et al. (16) \\
Endometrial cancer & - & 3.22 & Guh et al. (16) \\
Gall bladder disease & 1.43 & 2.32 & Guh et al. (16) \\
Osteoarthritis & 4.2 & 1.96 & Guh et al. (16) \\
Fatty liver & 3.53 & 3.53 & Li et al. (18) \\
\hline
\end{tabular}

cause (22). When it came to fatty liver, cirrhosis was used as the main cause for DALY loss (23). Twenty percent of those affected by non-alcoholic fatty liver disease (NAFLD) eventually develop non-alcoholic steatohepatitis (NASH) (24). Of those, $20 \%$ develop cirrhosis (25). DALYs per cirrhotic patient in the Eastern Mediterranean region was used as a proxy for Egypt.

\section{Economic Burden}

We focused on direct healthcare costs attributable to obesity. Direct non-healthcare costs, and indirect costs were not included in our analysis. We estimated the cost per patient for each disease, and then by sex we multiplied this value with the number of patients suffering from the disease and cared for and with the PAF. Then, we summed up the two values (males and females). We adjusted for the inflation when needed.
The costs of eight comorbidities (stroke, ischemic heart disease, depression, obstructive sleep apnea, osteoarthritis, endometrial cancer, gall bladder disease and fatty liver) were not available in the literature, so those costs were estimated through interviews with experts in each field.

For each comorbidity, the questionnaires for expert interviews were prepared based on cost components from published data. The questionnaires can be found in Supplementary Tables 2-9. The cost components were aggregated from the Health Insurance Organization (HIO) services price list, and the medication prices were aggregated from the public medication prices in the Egyptian market. Public prices were used to estimate medication costs because about $60 \%$ of the health spending in Egypt are out of pocket payments (26).

To avoid adding the costs for patients who are not treated, the cost values were multiplied by the percentage of treated population for each disease.

\section{Adjusting Values}

Most values abstracted from the literature were from 2017 (last reported), so they were adjusted to 2020, based on the adult population growth factor. 2017 population data was found at CAPMAS (27), while 2020 population was an estimate through CIA world factbook (28). An exchange rate of 15.85 was used to exchange USD to EGP throughout the study.

\section{RESULTS}

\section{Clinical Burden \\ Prevalence of Obesity}

According to "100 million health" survey, which was conducted in Egypt in 2019 and screened 49.7 million adult Egyptians $(\geq 18$ years old), 39.8\% of adult Egyptians suffered from obesity (BMI $\geq 30 \mathrm{~kg} / \mathrm{m}^{2}$ ). Obesity was more prevalent in adult females than 
TABLE 3 | Estimated numbers of adult males and females who suffered from a comorbidity due to obesity in 2020 in Egypt.

\begin{tabular}{|c|c|c|c|c|c|}
\hline Disease & PAF in males & PAF in females & $\begin{array}{l}\text { Numbers in adult male } \\
\text { population (2020) }\end{array}$ & $\begin{array}{c}\text { Numbers in adult female } \\
\text { population (2020) }\end{array}$ & $\begin{array}{c}\text { Total population } \\
\text { (2020) }\end{array}$ \\
\hline Diabetes mellitus & $61.8 \%$ & $85.0 \%$ & $3,004,347$ & $4,759,839$ & $7,764,186$ \\
\hline Hypertension & $19.9 \%$ & $41.3 \%$ & $2,077,436$ & $4,101,365$ & $6,178,802$ \\
\hline Ischemic heart disease & $49.9 \%$ & $62.5 \%$ & 565,470 & 459,645 & $1,025,115$ \\
\hline Hyperlipidemia & $18.3 \%$ & $27.3 \%$ & 957,917 & $2,176,623$ & $3,134,540$ \\
\hline Stroke & $13.1 \%$ & $19.5 \%$ & 75,234 & 123,304 & 198,538 \\
\hline Obstructive sleep apnea & $63.9 \%$ & $74.8 \%$ & $4,933,804$ & $4,327,953$ & $9,261,757$ \\
\hline Depression & $8.4 \%$ & $24.9 \%$ & 94,937 & 436,033 & 530,970 \\
\hline Colon and colorectal cancer & $21.9 \%$ & $24.6 \%$ & 2,587 & 2,185 & 4,772 \\
\hline Breast cancer & 0.00 & $6.0 \%$ & - & 6,031 & 6,031 \\
\hline Endometrial cancer & 0.00 & $52.4 \%$ & - & 5,944 & 5,944 \\
\hline Gall bladder disease & $11.3 \%$ & $39.5 \%$ & 18,337 & 132,525 & 150,862 \\
\hline Osteoarthritis & $48.6 \%$ & $32.2 \%$ & 826,810 & 570,284 & $1,397,094$ \\
\hline Fatty liver & $42.7 \%$ & $55.6 \%$ & $3,750,248$ & $4,730,231$ & $8,480,479$ \\
\hline
\end{tabular}

PAF, population attributable fraction.

adult males (49.5\% of Egyptian adult females suffered obesity compared to $29.5 \%$ for males).

\section{Patients With Diseases Attributable to Obesity}

Diabetes mellitus type 2 had the highest prevalence attributable to obesity in adult Egyptians. Eighty five percent of females and $62 \%$ of males with diabetes mellitus type 2 can be attributed to obesity, translating to $4,759,839$ and $3,004,347$ females and males, respectively. About 13 million adults suffered from sleep apnea and about 8.5 million suffered from fatty liver due to obesity. Hypertension caused by obesity affected about 6 million adults. The estimated numbers of adult males and females who developed certain comorbidities due to obesity in 2020 in Egypt are shown in Table 3.

\section{Mortality Attributable to Obesity}

In 2020, the estimated total number of deaths due to obesity was around 113 thousand which represents about $19 \%$ of the total estimated number of deaths in 2020 (29). Ischemic heart disease had the greatest share among obesity comorbidities causing mortalities, as it is a severe and common disease. The breakdown of mortality data is shown in Table 4.

\section{Humanistic Burden \\ Disability Adjusted Life Years}

Ischemic heart disease was responsible for most DALYs attributable to obesity. This exceeded 2 million DALYs, as ischemic heart disease is a major contributor to premature mortality. Diabetes mellitus type 2 came next at about 660 thousand DALYs, as it is quite prevalent and affects quality of life considerably. Obstructive sleep apnea followed, with around 290 thousand DALYs, then stroke (240 thousand DALYs) and hyperlipidemia (230 thousand DALYs). Other comorbidities had less contribution to DALYs. The total DALYs attributable to obesity in 2020 was estimated to be about 4 million. The breakdown of DALYs data is shown in Table 5.

\section{Economic Burden} Diabetes Mellitus Type 2

According to a study conducted in 2017 (30, 31), the estimated healthcare cost of diabetes mellitus in Egypt was 22.3 Bn EGP in 2015. This value was divided by the number of diabetes patients in 2015 to estimate the cost per patient. This cost was adjusted to the inflation rate based on the consumer price index $(32,33)$ to year 2019-which was the most recent-to be 4,445 EGP. Finally, the cost per patient was multiplied by the estimated number of patients who had diabetes due to obesity in 2020 to reach about 34.5 Bn EGP.

\section{Hypertension}

In 2013, a study assumed that medications represent around $80 \%$ of the cost of hypertension in Egypt (34). The total cost of hypertension drugs in Egypt was abstracted from the monthly drug consumption report by IQVIA from IMS drug consumption report (unpublished data), showing that around 5.5 Bn EGP are spent on hypertension drugs annually in 2019. These values were used to calculate the annual burden of hypertension attributable to obesity in Egypt. The value was not adjusted to the number of diagnosed patients, since all patients taking medications are already diagnosed. From this the estimated cost of hypertension due to obesity was $2.1 \mathrm{Bn}$ EGP.

\section{Hyperlipidemia}

The cost of hyperlipidemia treatment in Egypt was estimated to be around 9,109 EGP per patient annually (35). To estimate the total annual cost in Egypt, the proportion of treated patients was required, since some patients have the disease but are not treated or even diagnosed. The percentage of uncontrolled patients was estimated through a US based study (65.2\%) (36). This was used to estimate the total number treated in Egypt.

\section{Colon and Colorectal Cancer}

The estimated average cost of treating colorectal cancer per patient annually was 610 USD in Egypt (37). This 
TABLE 4 | Mortality attributable to obesity.

\begin{tabular}{|c|c|c|c|c|}
\hline \multirow{2}{*}{$\begin{array}{l}\text { Disease } \\
\\
\text { Diabetes } \\
\text { mellitus }\end{array}$} & \multicolumn{2}{|c|}{$\begin{array}{l}\text { Death cases } \\
\text { attributable to obesity }\end{array}$} & \multirow{2}{*}{$\begin{array}{c}\begin{array}{c}\text { Percentage } \\
\text { of total } \\
\text { deaths per } \\
\text { year* }\end{array} \\
1.31 \%\end{array}$} & \multirow{2}{*}{$\begin{array}{c}\begin{array}{c}\text { Male: female } \\
\text { ratio }\end{array} \\
0.76\end{array}$} \\
\hline & Total & 7,877 & & \\
\hline & Males & 3,407 & & \\
\hline & Females & 4,470 & & \\
\hline \multirow{3}{*}{$\begin{array}{l}\text { Ischemic heart } \\
\text { disease }\end{array}$} & Total & 94,575 & $15.71 \%$ & 1.65 \\
\hline & Males & 58,888 & & \\
\hline & Females & 35,687 & & \\
\hline \multirow[t]{3}{*}{ Stroke } & Total & 8,846 & $1.47 \%$ & 0.89 \\
\hline & Males & 4,171 & & \\
\hline & Females & 4,675 & & \\
\hline \multirow{3}{*}{$\begin{array}{l}\text { Colon and } \\
\text { colorectal } \\
\text { cancer }\end{array}$} & Total & 733 & $0.12 \%$ & 1.3 \\
\hline & Males & 414 & & \\
\hline & Females & 319 & & \\
\hline \multirow[t]{3}{*}{ Breast cancer } & Total & 243 & $0.04 \%$ & NA \\
\hline & Males & - & & \\
\hline & Females & 243 & & \\
\hline \multirow{3}{*}{$\begin{array}{l}\text { Endometrial } \\
\text { cancer }\end{array}$} & Total & 192 & $0.03 \%$ & \\
\hline & Males & - & & NA \\
\hline & Females & 192 & & \\
\hline \multirow{3}{*}{$\begin{array}{l}\text { Gall bladder } \\
\text { disease }\end{array}$} & Total & 341 & $0.06 \%$ & 0.45 \\
\hline & Males & 106 & & \\
\hline & Females & 235 & & \\
\hline \multirow{3}{*}{$\begin{array}{l}\text { Total annual } \\
\text { deaths } \\
\text { attributable to } \\
\text { obesity }\end{array}$} & Total & 112,807 & $18.73 \%$ & 1.48 \\
\hline & Males & 66,986 & & \\
\hline & Females & 45,821 & & \\
\hline
\end{tabular}

"Percentages are of the estimated total annual deaths in Egypt in 2020 (602, 152 deaths).

was used to estimate the cost for patients attributable to obesity. The percentage of diagnosed cases was calculated based on an epidemiological study in Egypt to be around $15 \%(38)$.

\section{Breast Cancer}

The average total cost of treating breast cancer in Egypt was estimated at 46,910 USD per patient (39). However, the annual cost was not indicated in the report, so the total cost was divided by the average number of years lived by breast cancer patients (6.06 years). This value was calculated from the data available through Globocan 2018 (40), resulting in an annual cost of 7,741 USD per patient.

To find the percentage of diagnosed cases, the number of diagnosed cases (38) was divided by the prevalence.
TABLE 5 | DALYs attributable to obesity.

\begin{tabular}{lccc}
\hline Disease & DALYs in males & DALYs in females & Total DALYs \\
\hline Ischemic heart disease & $1,504,408$ & 847,929 & $2,352,337$ \\
Diabetes mellitus type 2 & 284,946 & 373,117 & 658,063 \\
Obstructive sleep & 153,393 & 134,557 & 287,949 \\
apnea & & & \\
Stroke & 107,235 & 128,708 & 235,943 \\
Hyperlipidemia & 95,149 & 137,667 & 232,816 \\
Hypertension & 37,598 & 58,945 & 96,543 \\
Depression & 16,499 & 75,811 & 92,310 \\
Osteoarthritis & 26,284 & 17,939 & 44,223 \\
Fatty liver & 12,405 & 16,131 & 28,536 \\
Colon and colorectal & 12,499 & 9,683 & 22,182 \\
cancer & & & 10,557 \\
Gall bladder disease & 3,039 & 7,517 & 9,225 \\
Breast cancer & - & 9,225 & 6,765 \\
Endometrial cancer & - & 6,765 & $4,077,448$ \\
Total DALYS & $2,253,455$ & $1,823,993$ & \\
& & &
\end{tabular}

$D A L Y$ S, disability adjusted life years.

Table 6 shows the annual direct healthcare cost of obesity comorbidities. Diabetes mellitus and hyperlipidemia are responsible for the largest financial burden among the comorbidities, representing about $60 \%$ of the total direct health care cost. Osteoarthritis is a major contributor also to the total economic burden of obesity. The total annual cost of treatment of diseases attributable to obesity was estimated to be 62,413 million EGP.

\section{DISCUSSION}

Obesity is a leading cause of preventable death globally; (1) and Egypt is one of the leading countries in the prevalence of obesity worldwide (3). The burden of obesity might be overseen because obesity acts as a proxy to many comorbidities which in turn causes morbidity and mortality. We found no studies focused on evaluating the burden of obesity in Egypt. Our study focused on estimating the economic, and humanistic burden of obesity in Egypt. Estimating the magnitude of the issue is especially important to grab both the public attention, and decision makers to both facilitate individual actions and implement public health policies to alleviate the burden of obesity in Egypt.

The prevalence of obesity has increased in adults in Egypt to reach about $40 \%$ according to 100 million health survey (2019) compared to the $36 \%$ estimate of 2017 STEPwise survey (10). Obesity is more prevalent in Egyptian females compared to males (about 50\% compared to 30\% respectively). This could be probably attributed to the cultural factors, as females in Egypt are less likely to be involved in physical activities compared to males $(10,41)$.

The results revealed that nearly three quarters of adult diabetes mellitus type 2 cases in Egypt are attributable to obesity. Obesity is also the underlying disease for more than half of obstructive 
TABLE 6 | Annual direct healthcare cost due to obesity.

\begin{tabular}{|c|c|c|c|}
\hline Comorbidity & $\begin{array}{c}\text { Annual cost of } \\
\text { treatment } \\
\text { attributable to } \\
\text { obesity/million } \\
\text { EGP }\end{array}$ & $\begin{array}{c}\text { Percentage of } \\
\text { total attributable } \\
\text { cost }\end{array}$ & $\begin{array}{l}\text { Source of annual } \\
\text { cost estimation per } \\
\text { patient }\end{array}$ \\
\hline $\begin{array}{l}\text { Diabetes } \\
\text { mellitus }\end{array}$ & 34,512 & $55.3 \%$ & Assaad et al. (30) \\
\hline Hyperlipidemia & 9,936 & $15.9 \%$ & Shaheen et al. (35) \\
\hline Osteoarthritis & 7,876 & $12.6 \%$ & $\begin{array}{l}\text { Estimated based on } \\
\text { expert interviews }\end{array}$ \\
\hline Fatty liver & 2,881 & $4.6 \%$ & $\begin{array}{l}\text { Estimated based on } \\
\text { expert interviews }\end{array}$ \\
\hline $\begin{array}{l}\text { Obstructive } \\
\text { sleep apnea }\end{array}$ & 2,650 & $4.2 \%$ & $\begin{array}{l}\text { Estimated based on } \\
\text { expert interviews }\end{array}$ \\
\hline Hypertension & 2,097 & $3.4 \%$ & Ibrahim (34) \\
\hline $\begin{array}{l}\text { Ischemic heart } \\
\text { disease }\end{array}$ & 1,624 & $2.6 \%$ & $\begin{array}{l}\text { Estimated based on } \\
\text { expert interviews }\end{array}$ \\
\hline Depression & 440 & $0.7 \%$ & $\begin{array}{l}\text { Estimated based on } \\
\text { expert interviews }\end{array}$ \\
\hline Stroke & 269 & $0.4 \%$ & $\begin{array}{l}\text { Estimated based on } \\
\text { expert interviews }\end{array}$ \\
\hline Breast cancer & 101 & $0.2 \%$ & Skrundevskiy et al. (39) \\
\hline $\begin{array}{l}\text { Gall bladder } \\
\text { disease }\end{array}$ & 18 & $0.0 \%$ & $\begin{array}{l}\text { Estimated based on } \\
\text { expert interviews }\end{array}$ \\
\hline $\begin{array}{l}\text { Colon and } \\
\text { colorectal } \\
\text { cancer }\end{array}$ & 6 & $0.0 \%$ & Abotaleb (37) \\
\hline $\begin{array}{l}\text { Endometrial } \\
\text { cancer }\end{array}$ & 2 & $0.0 \%$ & $\begin{array}{l}\text { Estimated based on } \\
\text { expert interviews }\end{array}$ \\
\hline Total & $\begin{array}{c}\text { 62,413 million EGP } \\
\text { per year }\end{array}$ & $100 \%$ & \\
\hline
\end{tabular}

sleep apnea, ischemic heart disease, endometrial cancer and fatty liver cases in Egypt.

The comorbidities of obesity carry a substantial mortality risk causing around 19\% of annual mortalities in Egypt. Although female prevalence is higher, $59 \%$ of obesity attributable deaths are males. The main reason for that is ischemic heart disease, which caused around $84 \%$ of deaths attributable to obesity, and is dominant in males, with a male to female ratio of 1.65 .

Ischemic heart disease also contributes to the major portion of DALYs lost because of the early mortality, followed by diabetes mellitus which makes about $16 \%$ of total DALYs. Although obstructive sleep apnea does not contribute to death, it makes up about $7 \%$ of total DALYs.

Concerning the economic burden of obesity, chronic diseases have the lion's share, with diabetes mellitus type 2 accounting for more than half of the annual cost followed by hyperlipidemia, and osteoarthritis at around 30\% combined. Although cancer treatment is comparatively more expensive, cancers did not make up a large chunk in either costs, DALYs, or deaths because of their lower prevalence compared to chronic diseases.

Our study shows that there has been an increase in the burden of obesity in recent years, where the burden of obesity in the Eastern Mediterranean region study in 2015 (15) estimated lower values for high BMI attributable deaths and DALYs than the our study. In 2015, the study estimated 90,774 attributable deaths in Egypt, while our results showed an increase to reach 112,807 attributable deaths in 2020, translating to an increase from 16 (42) to $19 \%$ of the total annual deaths. For DALYs, an increase was also observed reaching about 1 million more DALYs lost. After adjusting to population growth, obesity attributable DALYs increased from 3.29 to $3.92 \%$ in the total population. Our methodology is a bit different than the above-mentioned study, but the results are consistent and show that obesity causes tremendous losses concerning mortality and quality of lives.

Our findings have some policy implications, as they show that effective prevention of obesity in Egypt would result in a huge health benefit. There are several policies and recommendations that could be applied to decrease the prevalence of obesity. The following examples from a recent systematic review could be implemented in Egypt: incentivizing healthy food, portion size restrictions, taxation and dedicated tax revenue for obesity prevention, promoting physical activity, certain food and beverage restriction combined with nutrition education at schools (43). The WHO regional office has published proposed policy priorities for preventing obesity and diabetes in the Eastern Mediterranean Region in 2017 (44). The policy recommendations included in this report could help in decreasing obesity and its burden if implemented. Learnings and recommendations about health policies and interventions from other countries aiming for obesity reduction can be beneficial; however, first, the feasibility of selected policies or health interventions needs to be evaluated nationally from both a regulatory and cultural perspective.

Our study has certain limitations. Due to the lack of complete and reliable local data, it was based on a mixture of primary and secondary data. As many less important comorbidities were not included in the analysis, our disease burden estimates are conservative from this perspective. Since some comorbidities mainly lead to death via other diseases and complications (e.g., hypertension, hyperlipidemia, sleep apnea, depression, osteoarthritis, and fatty liver), the number of deaths directly coded as death due to these diseases underestimate their true role in the mortality statistics. This way we somewhat underestimated the true population fraction of mortality, but only to a small extent, as the major consequences of these conditions were included as comorbidities in the calculations. On the other hand, we could not avoid double counting some cost items, as the cost of diabetes included the cost of the management of its complications, too. Unfortunately, the cost of complications of diabetes was not available by complication, thus we could not correct for this. However, as only a fraction of strokes and ischemic heart diseases is due to diabetes and the proportion of the cost of these diseases is only small in the total direct healthcare cost of obesity, the size of the error is minor. Also, direct non-healthcare costs due to obesity, as well as indirect costs were not considered in this study, this way counterbalancing the double counting of some other cost items. A limited number of expert interviews were conducted to estimate the annual cost of comorbidities, which limits the generalizability of the cost data. Further questionnaires and research should be conducted to have better estimates of comorbidities' annual cost. 
Some methodological issues contribute to limitations, too. The adult population definition was different among different sources; 100 million health survey included adults aged not $<18$, while STEPwise survey included adults aged 15-69 and sleep apnea was estimated for a population aged 30-60 years old. Also, hyperlipidemia DALY values were found for a population above 30 only and were estimated for hypercholesterolemia not hyperlipidemia which were assumed equal. For the relative risks of obstructive sleep apnea and fatty liver, there was no differentiation by sex. For fatty liver disease, the references did not mention the breakdown of prevalence by males and females. In these cases, it was assumed that the values are equal for both sexes. The DALY calculation of fatty liver disease was based on the burden caused by liver cirrhosis. Some estimates were not found specifically for Egypt, then values from other countries were used. For hyperlipidemia, the exact percentage of untreated patients was not available, so a proxy was used, based on the percentage of uncontrolled population. Nevertheless, these minor technical issues could not substantially bias the results. Furthermore, we believe, that utilization of these data for research facilitates the improvement of the quality of data.

In conclusion, obesity is a major contributor to ill-health and health expenditure in Egypt. It is a risk factor of several diseases, of which some are very severe, like heart diseases and stroke, and other are milder but highly prevalent among people with obesity. Consequently, obesity causes huge clinical, humanistic, and economic burden to Egyptians as individuals and as a society. More studies are required to evaluate different interventions and policies that can reduce obesity in Egypt and alleviate the impact of obesity on health.

\section{DATA AVAILABILITY STATEMENT}

Publicly available datasets were analyzed in this study. This data can be found at: Several data sources were used in the article. Some came from publicly available datasets found in the references. Others came from a third party. The data that came from a third party are: 1-Data from $100 \mathrm{M}$ health survey, Requests to access these datasets should be directed to [Galal Elshishiney, elshishiney@yahoo.com] 2-Data from IMS reports through Novo Nordisk, Requests to access these datasets should be directed to [Waleed Taha,wtah@novonordisk.com].

\section{ETHICS STATEMENT}

Ethical review and approval was not required for the study on human participants in accordance with the local legislation and institutional requirements. Written informed consent for participation was not required for this study in accordance with the national legislation and the institutional requirements.

\section{AUTHOR CONTRIBUTIONS}

$\mathrm{ZV}, \mathrm{SA}, \mathrm{AF}, \mathrm{BE}$, and $\mathrm{EB}$ conceptualized the project protocol. AF and $\mathrm{BE}$ conducted the analysis and calculations. MA, AE, IE, NE, and EA-M were the experts consulted throughout the steps of research process. GE advised for the data coming from national surveys. BE prepared the draft manuscript. ZV supervised all the scientific steps and provided comments. DT ensured the medical accuracy of the information. All authors revised, commented and approved the final manuscript.

\section{FUNDING}

This study was funded by Novo Nordisk Egypt.

\section{ACKNOWLEDGMENTS}

We acknowledge the efforts of Omar Fasseeh and Noha Soliman for collecting the data and conducting the expert interviews. We acknowledge also the information provided by the experts including: Professor Morsi Arab (Former vice president of the International Diabetes Federation), Dr. Ahmed Rasmy (physician at the Medical Research Institute, Alexandria), Professor Nashwa Abdelwahab (Professor of chest diseases, Alexandria University), Dr. Islam Korayem (liver and bile duct surgeon, Alexandria University), Professor Hanan Hosny Nouh (Professor of gastroenterology, Alexandria University), Dr. Mohamed Nageb (Gynecology, obstetrics and IVF specialist, Alexandria university), Dr. Tahia Elsebakhi (psychiatric at Mohamed Farid polyclinic-HIO, Alexandria), Dr. Ahmed Khalifa (Neurologist at Gamal Abd-Elnaser HospitalHIO, Alexandria), Dr. Ahmed Abd-Emaksoud (Orthopedic surgeon at Gamal Abd-Elnaser Hospital- HIO, Alexandria), Dr. Adel Abu-Shousha (Orthopedic surgeon at Karmouz HospitalHIO, Alexandria), Dr. Yousef Gerges (Rheumatologist at Mohamed Farid poly clinic-HIO, Alexandria), Dr. Hany Elsabaa (Cardiology consultant at Gamal Abd-Elnaser Hospital-HIO, Alexandria), Dr. Lobna Elgamal (ICU consultant at Gamal AbdElnaser Hospital-HIO, Alexandria).

\section{SUPPLEMENTARY MATERIAL}

The Supplementary Material for this article can be found online at: https://www.frontiersin.org/articles/10.3389/fpubh. 2021.718978/full\#supplementary-material

\section{REFERENCES}

1. Mehrzad R. The global impact of obesity. In: Mehrzad R, editor. Obesity. Amsterdam: Elsevier (2020). p. 55-72.

2. Our World in Data. Share of deaths attributed to obesity, 1990 to 2017. Available online at: https://ourworldindata.org/grapher/share-of-deathsobesity?tab=chart\&country=OWID_WRL (accessed July 7, 2021).

3. ProCon.org. Global Obesity Levels. (2020). Available online at: https://obesity.procon.org/global-obesity-levels/ (accessed June 28, 2020).

4. World Health Organization. Noncommunicable diseases. (2021). Available online at: https://www.who.int/news-room/ fact-sheets/detail/noncommunicable-diseases (accessed July 14, 2021). 
5. Abolfotouh MA, Soliman LA, Mansour E, Farghaly M, El Dawaiaty AA. Central obesity among adults in Egypt: prevalence and associated morbidity. East Mediterr Health J. (2008) 14:57-68.

6. Devleesschauwer B, De Noordhout CM, Smit GSA, Duchateau L, Dorny P, Stein C, et al. Quantifying burden of disease to support public health policy in Belgium: opportunities and constraints. BMC Public Health. (2014) 14:1-8. doi: 10.1186/1471-2458-1 4-1196

7. Katz DL. Perspective: obesity is not a disease. Nature. (2014) 508:S57. doi: $10.1038 / 508$ S57a

8. ICD-10 Version:2019. (2019). Available online at: https://icd.who.int/ browse10/2019/en\#/ (accessed December 17, 2020).

9. World Health Organization. Obesity. Available online at: https:// www.who.int/health-topics/obesity\#tab=tab_1 (accessed October 26, 2020).

10. World Health Organization. Egypt National STEPwise Survey For Noncommunicable Diseases Risk Factors Report. (2017). Available online at: https://www.who.int/ncds/surveillance/steps/Egypt_National_STEPwise_ Survey_For_Noncommunicable_Diseases_Risk_Factors_2017_Report.pdf? $\mathrm{ua}=1$ (accessed October 11, 2020).

11. James SL, Abate D, Abate KH, Abay SM, Abbafati C, Abbasi N, et al. Global, regional, and national incidence, prevalence, and years lived with disability for 354 diseases and injuries for 195 countries and territories, 1990-2017: a systematic analysis for the Global Burden of Disease Study 2017. Lancet. (2018) 392:1789-858. doi: 10.1016/S0140-6736(17)3 2154-2

12. Institute for Health Metrics and Evaluation. Available online at: http://www. healthdata.org/ (accessed June 16, 2020).

13. Franklin KA, Lindberg E. Obstructive sleep apnea is a common disorder in the population-a review on the epidemiology of sleep apnea. J Thorac Dis. (2015) 7:1311. doi: 10.3978/j.issn.2072-1439.2015.06.11

14. Binobaid AO, Alalwan MA, Almalki AHA, Almaghrabi SK, Sharif MK, Alomair AA, et al. Prevalence and risk factors of fatty liver among adults. Egypt J Hosp Med. (2018) 31:1-6. doi: 10.1111/j.1440-1746.2005.04086.x

15. GBD 2015 Eastern Mediterranean Region Obesity Collaborators. Burden of obesity in the Eastern Mediterranean Region: findings from the Global Burden of Disease 2015 study. Int J Public Health. (2018) 63:16576. doi: 10.1007/s00038-017-1002-5

16. Guh DP, Zhang W, Bansback N, Amarsi Z, Birmingham $\mathrm{CL}$, Anis AH. The incidence of co-morbidities related to obesity and overweight: a systematic review and metaanalysis. BMC Public Health. (2009) 9:88. doi: 10.1186/1471-2 458-9-88

17. Carol D. Causes of Obstructive Sleep Apnea. (2019). Available online at: https://www.webmd.com/sleep-disorders/ sleep-apnea/obstructive-sleep-apnea-causes (accessed June $16,2020)$.

18. Li L, Liu DW, Yan HY, Wang ZY, Zhao SH, Wang B. Obesity is an independent risk factor for non-alcoholic fatty liver disease: evidence from a metaanalysis of 21 cohort studies. Obes Rev. (2016) 17:510-9. doi: 10.1111/obr. 12407

19. Jee SH, Sull JW, Park J, Lee SY, Ohrr H, Guallar E, Samet JM. Body-mass index and mortality in Korean men and women. N Engl J Med. (2006) 355:779-87. doi: 10.1056/NEJMoa054017

20. Fu T, Wen $T$, Yeh $P$, Chang $H$. Costs of metabolic syndromerelated diseases induced by obesity in Taiwan. Obes Rev. (2008) 9:68-73. doi: 10.1111/j.1467-789X.2007.00441.x

21. World Health Organization. Global health risks: mortality and burden of disease attributable to selected major risks. (2009). Available online at: https://apps.who.int/iris/handle/10665/44203 (accessed July $7,2020)$.

22. Hillman D, Mitchell S, Streatfeild J, Burns C, Bruck D, Pezzullo L. The economic cost of inadequate sleep. Sleep. (2018) 41:zsy083. doi: 10.1093/sleep/zsy083

23. Asrani SK, Devarbhavi H, Eaton J, Kamath PS. Burden of liver diseases in the world. J Hepatol. (2019) 70:151-71. doi: 10.1016/j.jhep.2018. 09.014
24. Hughes AN, Oxford JT. A lipid-rich gestational diet predisposes offspring to nonalcoholic fatty liver disease: a potential sequence of events. Hepat Med. (2014) 6:15. doi: 10.2147/HMER.S 57500

25. Canadian Liver Foundation. Fatty Liver Disease. (2019). Available online at: https://www.liver.ca/patients-caregivers/liver-diseases/fatty-liver-disease/ (accessed June 16, 2020).

26. Rashad AS, Sharaf MF. Catastrophic and impoverishing effects of outof-pocket health expenditure: new evidence from Egypt. Am J Econ. (2015) 5:526-33. Available online at: https://erf.org.eg/publications/ catastrophic-and-impoverishing-effects- of-out-of- pocket-healthexpenditure-new-evidence-from-egypt/

27. CAPMAS. Statistical Yearbook 2020 (2020). Available online at: https://www. capmas.gov.eg/Pages/StaticPages.aspx?page_id=5034 [in Arabic] (accessed June 23, 2020).

28. Central Intelligence Agency. Field Listing: Age structure-The World Factbook. (2020). Available online at: https://www.cia.gov/ library/publications/the-world-factbook/fields/341.html (accessed October 27, 2020).

29. Macrotrends. Egypt Death Rate 1950-2020. (2020). Available online at: https:// www.macrotrends.net/countries/EGY/egypt/death-rate (accessed June 23, 2020).

30. Assaad-Khalil S, Elebrashy IN, Afify Y, Abdelmordy B, Zakaria W, Aboushady R, et al. The financial burden of diabetes mellitus type 1 and type 2 in Egypt. Value Health. (2017) 20:A477. doi: 10.1016/j.jval.2017. 08.447

31. Anan I, Hassan Z, Noaman S, Shanan N, Raed M, El-Hady O, et al. Diabetes Briefing Book Egypt. Cairo. (2017). p. 24.

32. Knoema. Egypt Consumer price index, 1960-2019. (2019). Available online at: https://knoema.com/atlas/Egypt/topics/Economy/ Inflation-and-Prices/Consumer-price-index (accessed November 18,2020 ).

33. Egypt Economy Forecast \& Outlook. Egypt Inflation Rate (CPI). (2019). Available online at: https://www.focus-economics.com/country-indicator/ egypt/inflation (accessed January 1, 2021).

34. Ibrahim MM. Problem of hypertension in Egypt. Egypt Heart J. (2013) 65:233-4. doi: 10.1016/j.ehj.2013. 03.005

35. Shaheen S, Elserafy AS, Amin M, Hassan R, Issak ER. Brand versus generic rosuvastatin in Egyptian patients with hyperlipidemia; cost-minimization analysis. Int J Clin Med. (2019) 10:631-8. doi: 10.4236/ijcm.2019.10 12052

36. Zallman L, Himmelstein DH, Woolhandler S, Bor DH, Ayanian JZ, Wilper AP, et al. Undiagnosed and uncontrolled hypertension and hyperlipidemia among immigrants in the US. J Immigr Minor Health. (2013) 15:85865. doi: 10.1007/s10903-012-9695-2

37. Abotaleb A. Cost of illness for colorectal cancer at low middle income countries Egypt case. Ann Oncol. (2018) 29:v545. doi: 10.1093/annonc/mdy151.194

38. Ibrahim AS, Khaled HM, Mikhail NN, Baraka H, Kamel H. Cancer incidence in Egypt: results of the national population-based cancer registry program. J Cancer Epidemiol. (2014) 2014:437971 doi: 10.1155/2014/4 37971

39. Skrundevskiy AN, Omar OS, Kim J, Soliman AS, Korolchuk TA, Wilson FA. Return on investment analysis of breast cancer screening and downstaging in Egypt: implications for developing countries. Value Health Reg Issues. (2018) 16:22-7. doi: 10.1016/j.vhri.2018.01.006

40. Bray F, Ferlay J, Soerjomataram I, Siegel RL, Torre LA, Jemal A. Global cancer statistics 2018: GLOBOCAN estimates of incidence and mortality worldwide for 36 cancers in 185 countries. CA Cancer J Clin. (2018) 68:394424. doi: 10.3322 /caac. 21492

41. Alebshehy R, Shuaib NM, Mbako JD, Barffo D, Nuotol RK. Determinant analysis of obesity among adult females in Egypt. Egypt J Hosp Med. (2016) 65:662-9. doi 10.12816/0033779 doi: 10.12816/0033779

42. The World Bank. Death rate, crude (per 1,000 people)-Egypt, Arab Rep. Available online at: https://data.worldbank.org/indicator/SP.DYN.CDRT.IN? locations=EG (accessed July 13, 2021). 
43. Chriqui JF. Obesity prevention policies in US states and localities: lessons from the field. Curr Obes Rep. (2013) 2:200-10. doi: 10.1007/s13679-013-0063-x

44. Alwan A, McColl K, Al-Jawaldeh A, World Health Organization. Proposed Policy Priorities for Preventing Obesity and Diabetes in the Eastern Mediterranean Region. Cairo: WHO Regional Office for the Eastern Mediterranean (2017).

Conflict of Interest: Syreon Middle East was a contractual partner of Novo Nordisk Egypt. AF, SA, and ZV are shareholders in Syreon Middle East. BE is an employee at Syreon Middle East. DT and EB are employees at Novo Nordisk Egypt.

The remaining authors declare that the research was conducted in the absence of any commercial or financial relationships that could be construed as a potential conflict of interest.
Publisher's Note: All claims expressed in this article are solely those of the authors and do not necessarily represent those of their affiliated organizations, or those of the publisher, the editors and the reviewers. Any product that may be evaluated in this article, or claim that may be made by its manufacturer, is not guaranteed or endorsed by the publisher.

Copyright $\odot 2021$ Aboulghate, Elaghoury, Elebrashy, Elkafrawy, Elshishiney, AbulMagd, Bassiouny, Toaima, Elezbawy, Fasseeh, Abaza and Vokó. This is an openaccess article distributed under the terms of the Creative Commons Attribution License (CC BY). The use, distribution or reproduction in other forums is permitted, provided the original author $(s)$ and the copyright owner(s) are credited and that the original publication in this journal is cited, in accordance with accepted academic practice. No use, distribution or reproduction is permitted which does not comply with these terms. 